\title{
Effectiveness of Liraglutide and Lixisenatide in the Treatment of Type 2 Diabetes: Real-World Evidence from The Health Improvement Network (THIN) Database in the United Kingdom
}

\author{
Michael Feher · Gabriela Vega-Hernandez • Emina Mocevic • \\ Brian Buysse · Melissa Myland · Geraldine S. Power • \\ Lise L. Nystrup Husemoen · Joseph Kim • Daniel R. Witte
}

Received: December 15, 2016 / Published online: March 9, 2017

(C) The Author(s) 2017. This article is published with open access at Springerlink.com

\section{ABSTRACT}

Introduction: The glucagon-like peptide-1 receptor agonists liraglutide and lixisenatide are effective at reducing glycated hemoglobin (HbA1c) levels in patients with type 2 diabetes mellitus (T2DM). Although liraglutide has demonstrated superior efficacy in head-to-head

Enhanced content To view enhanced content for this article go to http://www.medengine.com/Redeem/ 0297F060303E6D59.

M. Feher

Chelsea and Westminster Hospital, London, UK

G. Vega-Hernandez ( $₫)$

Novo Nordisk, West Sussex, UK

e-mail: gvg@novonordisk.com

E. Mocevic · L. L. Nystrup Husemoen

Novo Nordisk, Søborg, Denmark

B. Buysse - M. Myland - G. S. Power · J. Kim NEMEA Centre of Excellence for Retrospective Studies, QuintilesIMS, London, UK

J. Kim

Faculty of Epidemiology and Population Health, London School of Hygiene and Tropical Medicine, London, UK

D. R. Witte

Department of Public Health, Aarhus University, Aarhus, Denmark

D. R. Witte

Danish Diabetes Academy, Odense, Denmark clinical trials, real-world evidence of comparative effectiveness is lacking. This observational study aimed to assess the effectiveness of liraglutide versus lixisenatide in UK clinical practice.

Methods: Electronic medical records from The Health Improvement Network (THIN) UK primary care database were analyzed. Patients aged $\geq 18$ years, diagnosed with T2DM, and prescribed liraglutide or lixisenatide between 01 May 2013 and 31 December 2015 were included in the study. Adjusted linear regression models compared the difference in mean change in HbA1c, body mass index (BMI), and systolic blood pressure (SBP) after 12-month follow-up. The proportion of patients achieving glycemic control (HbA1c <6.5\%, <7.0\%, <7.5\%); HbA1c reduction $>1 \%$; and weight reduction $\geq 3 \%$ within 12 months were determined. Cox proportional hazards modeling was used to evaluate the effect of treatment on time to achieving HbA1c and weight reduction targets. Healthcare resource use (HCRU) (GP, secondary care, hospitalizations) was compared using analysis of covariance.

Results: The primary outcome was assessed in 579 liraglutide and 213 lixisenatide new users. Fully adjusted linear regression indicated that liraglutide reduced HbA1c significantly more than lixisenatide (mean treatment difference -0.30 ; 95\% CI $-0.56,-0.04 ; p=0.025)$. Compared to lixisenatide, liraglutide recipients were 2.5 times more likely to achieve HbA1c $<6.5 \%$ 
$(p=0.0002)$. Liraglutide users were also more likely to achieve HbA1c $<7.0 \%$ (HR 2.10; $p<0.0001$ ), $<7.5 \%$ (HR 1.65; $p<0.0001$ ), and $>1 \%$ HbA1c reduction (HR 1.29; $p=0.0002$ ). BMI and SBP reductions were greater for the liraglutide group but results were not significant. HCRU was comparable between treatment groups.

Conclusion: These results from the THIN database indicate that liraglutide treatment provided better outcomes related to glycemic control.

Funding: Novo Nordisk.

Keywords: GLP-1 RA; HbA1c; Liraglutide; Lixisenatide; The Health Improvement Network; THIN; Type 2 diabetes

\section{INTRODUCTION}

In the management of type 2 diabetes mellitus (T2DM), the National Institute for Health and Care Excellence (NICE) guidelines in the UK recommend a patient-centered approach to achieving and maintaining glycemic control by individualizing target glycated hemoglobin (HbA1c) levels [1]. Although glycemic control is considered on a case-by-case basis, an HbA1c target of $6.5 \%(48 \mathrm{mmol} / \mathrm{mol})$ is recommended for most patients with T2DM. Following drug intensification, a secondary target of $7.0 \%$ $(53 \mathrm{mmol} / \mathrm{mol})$ is suggested and $7.5 \%$ (58 $\mathrm{mmol} / \mathrm{mol}$ ) is considered the threshold for further drug escalation [2].

Glucagon-like peptide-1 receptor agonists (GLP-1 RAs) are currently recommended as third-line treatment in diabetes management in UK clinical practice [2]. Liraglutide once daily (Victoza, Novo Nordisk, Bagsvaerd, Denmark) and lixisenatide once daily (Lyxumia, Sanofi-Aventis Groupe, Paris, France) are two GLP-1 RAs that have demonstrated clinical efficacy in patients with T2DM in numerous clinical studies [3-7]. Liraglutide was approved in the EU in 2009 and lixisenatide gained approval in 2013. Liraglutide and lixisenatide (as add-on to metformin) have been compared in randomized, open-label, parallel group trials $[4,6]$, where liraglutide was more effective than lixisenatide in improving glycemic control [6]. However, to our knowledge, no studies have compared the effectiveness of liraglutide to lixisenatide in patients treated in real-world clinical practice.

This study aimed to assess the effectiveness of liraglutide in comparison to lixisenatide in adult T2DM patients treated in UK primary care by using The Health Improvement Network (THIN) database. Effectiveness was determined by assessing the effects of these treatments on HbA1c levels, body mass index (BMI), and systolic blood pressure (SBP) during the 12 months following initiation of therapy. Healthcare resource utilization (GP, secondary care, and hospitalizations) between users of liraglutide versus lixisenatide was also investigated.

\section{METHODS}

\section{Study Design and Data Source}

This observational study of adults with T2DM utilized electronic medical record (EMR) data from the THIN database, a large UK primary care data source. THIN contains anonymized medical records for over 13 million patients, of which over 3.5 million are currently active, representing nearly $6 \%$ of the UK population. Studies have demonstrated the validity of THIN data for use in pharmacoepidemiological studies [8-10] and its generalizability to the UK in terms of demographics and diabetes prevalence [11].

The period of observation was from 01 May 2013 (to coincide with licensing of lixisenatide in the UK) to 31 December 2015. The index date was the first recorded prescription issued for liraglutide or lixisenatide within the study period as identified by relevant drug codes within THIN. Clinical effectiveness was assessed from index date to 12 months follow-up. Baseline HbA1c, SBP, body weight, and BMI measurements within the 6 months prior to index date were included to reflect the UK National Institute of Health and Care Excellence (NICE) recommendation of HbA1c measurements every 3-6 months [2]. Similarly, 12-month follow-up measurements were assessed at the 12-month follow-up date \pm 3 months. Healthcare resource 
use was assessed from index date to 12 months post-index. The study was reviewed and approved by the UK Independent Scientific Review Committee (SRC) under protocol 16THIN050. The analysis does not contain any new studies with human or animal subjects performed by any of the authors.

\section{Study Population}

Patients were eligible for inclusion in the study population if they fulfilled all of the following criteria: (i) at least one new prescription of liraglutide or lixisenatide between 01 May 2013 and 31 December 2015, (ii) a recorded diagnosis of T2DM at any time prior to or on index (based on Read codes), (iii) $\geq 18$ years at index, and (iv) a minimum of 6 months of medical history pre-index. Exclusion criteria were (i) diagnosis of type 1 diabetes mellitus at any time, (ii) record of gestational diabetes within 12 months of index date, (iii) first prescription for liraglutide prior to 01 May 2013, (iv) insulin prescription prior to index, or (v) history of malignancy prior to index date. Patients were followed from liraglutide/lixisenatide initiation (index date) until the earliest of (i) record of insulin prescription, (ii) transfer out of practice/ death, or (iii) end of the study time period. Cohorts were constructed from the main study population for each outcome of interest on the basis of availability of follow-up measurements in order to maximize the populations available for assessment.

\section{Treatment Groups}

Liraglutide prescriptions were categorized as the following: all doses (any exposure to all available prescribed doses [0.6 mg, $1.2 \mathrm{mg}, 1.8 \mathrm{mg}$ per day] during the study period); $1.2 \mathrm{mg}$ category, average daily dose (ADD) $0.6-1.5 \mathrm{mg}$; and liraglutide $1.8 \mathrm{mg}$ category, ADD >1.5-2.1 mg [12]. ADD was calculated as the sum of the prescribed number of units (pens) multiplied by the total dosage in each unit (mg), divided by the sum of the days covered by the prescriptions. For lixisenatide, the standard $20 \mu \mathrm{g}$ dose per day was used.

\section{RESULTS}

\section{Cohort Sizes and Baseline Characteristics}

The primary outcome was the absolute change in $\mathrm{HbA} 1 \mathrm{c}$ at 12 months from index date. Secondary endpoints included (i) change in BMI and SBP at 12 months from index (Fig. 1a). Of the 1736 liraglutide users, 914 (52.6\%) were prescribed an average dose of $1.2 \mathrm{mg}, 93$ (5.4\%) were prescribed an average dose of $1.8 \mathrm{mg}$, and for $729(42.0 \%)$ patients the dose was unspecified. On the basis of availability of outcome measurements, cohort 1 for both liraglutide and lixisenatide treatment groups was divided into five cohorts for each outcome of interest as outlined in Fig. 1a, with cohorts 2 and 3 subdivided into a further three categories according to baseline HbA1c (Fig. 1b).

For the baseline cohort (cohort 1), the mean age of patients in the lixisenatide group (57.2 years, SD 10.7) was slightly greater than those in the liraglutide group (55.8 years, SD 10.7). Mean weight and BMI were comparable for both treatment groups $(107.0 \mathrm{~kg}$, SD 20.7; $37.6 \mathrm{~kg} / \mathrm{m}^{2}$, SD 6.6 for lixisenatide vs. $109.9 \mathrm{~kg}$, SD $22.5 ; 38.1 \mathrm{~kg} / \mathrm{m}^{2}$, SD 7.2 for liraglutide); however, almost $30 \%$ of all patients had missing weight data. Mean HbA1c levels at baseline were high in both treatment groups but slightly higher in patients prescribed lixisenatide (9.64\%, SD 1.53 lixisenatide vs. 9.49\%, SD 1.63 liraglutide). Mean baseline SBP was also elevated but comparable between cohorts $(133 \mathrm{mmHg}$, SD 14 for lixisenatide vs. $134 \mathrm{mmHg}$, SD 15 for liraglutide) (Table 1).

\section{Treatment Effects}

Unadjusted analyses demonstrated reductions in absolute change in HbA1c after 12 months for both liraglutide and lixisenatide initiators in cohort 2 (Fig. 2), with greater reductions observed in the liraglutide group $(-0.93 \%$ liraglutide vs. $-0.70 \%$ lixisenatide) (Fig. 2a). Using the change in estimate approach, no variables altered the treatment coefficient by more than $10 \%$, but all were entered into the fully adjusted model as a sensitivity analysis 

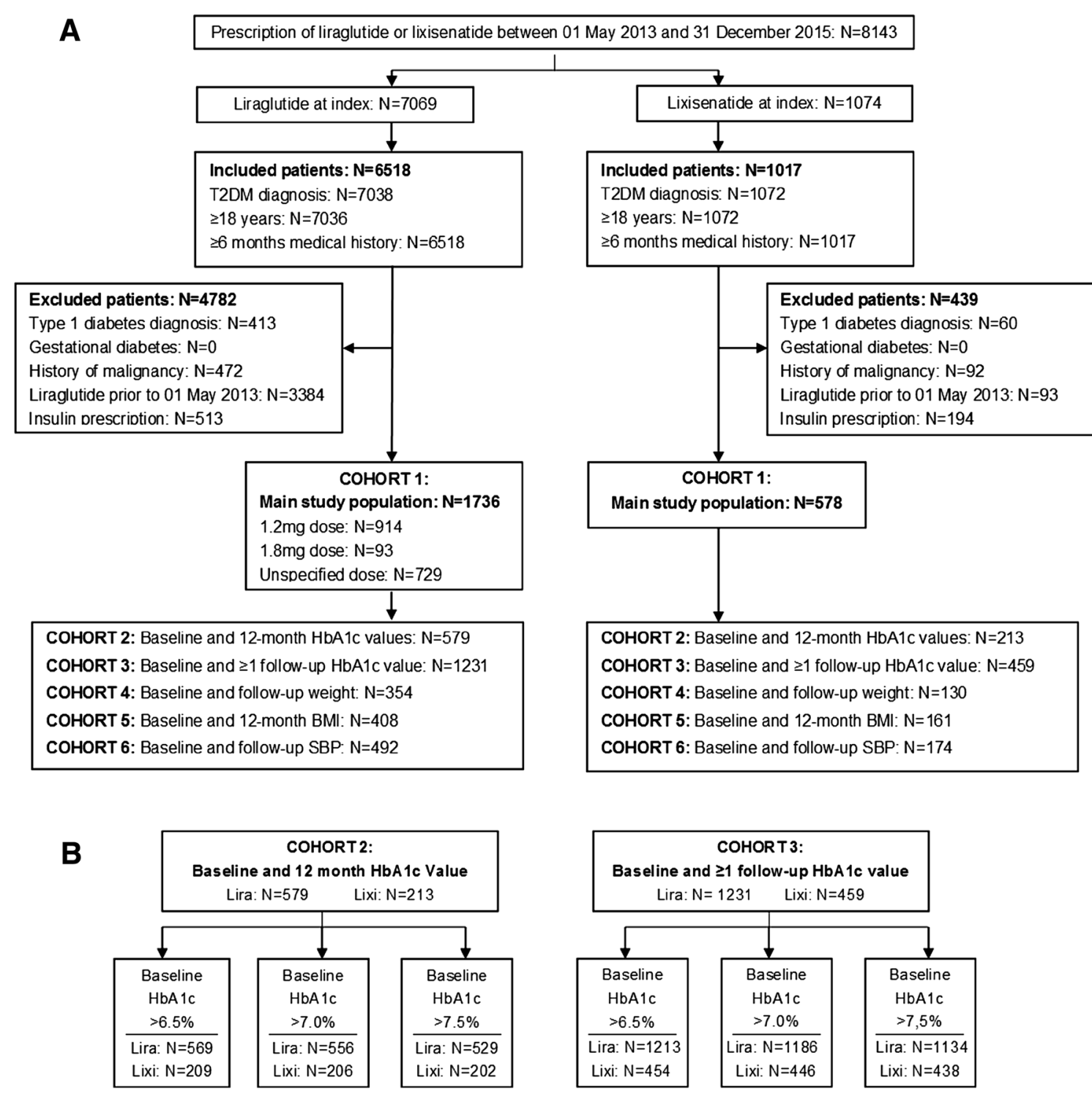

Fig. 1 a THIN study cohort analysis diagram for main baseline study population (cohort 1 ) and cohorts for each outcome of interest according to availability of follow-up measurements. b Subdivision of cohorts 2 and 3 into

(Table 2). The fully adjusted linear regression model for mean HbA1c change confirmed a greater mean change in HbA1c for the liraglutide group compared with the lixisenatide group $(-0.30,95 \%$ CI -0.56 to -0.04 , $p=0.025)$. Linear regression analyses adjusted only for baseline HbA1c (i.e., the baseline or null model) demonstrated a similar result $(-0.28,95 \% \mathrm{CI}-0.54$ to $-0.02, p=0.038)$. The magnitude of the coefficient for the sensitivity

categories according to baseline HbAlc. HbAlc glycated hemoglobin, SBP systolic blood pressure

analyses using a mixed linear regression model was very similar to the null model $(-0.27,95 \%$ CI -0.55 to $0.01, p=0.058)$, suggesting that clustering of patients within practice did not affect the model.

A greater proportion of the liraglutide group compared to the lixisenatide group in cohort 3 achieved glycemic control targets of HbA1c $<6.5 \%(10.8 \%$ vs. $4.0 \%), \quad<7.0 \%(24.1 \%$ vs. $11.7 \%$ ), $<7.5 \%$ (36.0\% vs. $23.3 \%$ ) (Fig. 3 ), and 
Table 1 Baseline characteristics of patients prescribed liraglutide (all doses [0.6 mg, $1.2 \mathrm{mg}$, and $1.8 \mathrm{mg}$ per day], and separately for $1.2 \mathrm{mg}$ and $1.8 \mathrm{mg}$ per day) or lixisenatide ( $20 \mu \mathrm{g}$ per day)

\begin{tabular}{|c|c|c|c|c|}
\hline & \multicolumn{3}{|l|}{ Liraglutide } & \multirow{2}{*}{$\begin{array}{l}\text { Lixisenatide } \\
20 \mu \mathrm{g}(N=578)\end{array}$} \\
\hline & All doses $(N=1736)$ & $1.2 \mathrm{mg}(N=914)$ & $1.8 \mathrm{mg}(N=93)$ & \\
\hline \multicolumn{5}{|l|}{$\overline{\text { Age (years) }}$} \\
\hline Mean (SD) & $55.8(10.7)$ & $55.8(10.3)$ & $55.3(10.7)$ & $57.2(10.7)$ \\
\hline Unknown/missing (\%) & 0 & 0 & 0 & 0 \\
\hline \multicolumn{5}{|l|}{ Sex, $n(\%)$} \\
\hline Male & $951(54.8)$ & $511(55.9)$ & $57(61.3)$ & $295(51.0)$ \\
\hline Female & $785(45.2)$ & $403(44.1)$ & $36(38.7)$ & $283(49.0)$ \\
\hline Unknown/missing (\%) & 0 & 0 & 0 & 0 \\
\hline \multicolumn{5}{|l|}{ Smoking status, $n(\%)^{\mathrm{a}}$} \\
\hline Current & $216(12.4)$ & $106(11.6)$ & $6(6.5)$ & $91(15.7)$ \\
\hline Former & $539(31.0)$ & $266(29.1)$ & $35(37.6)$ & $190(32.9)$ \\
\hline Never & $612(35.3)$ & $330(36.1)$ & $32(34.4)$ & $207(35.8)$ \\
\hline Unknown/missing (\%) & $369(21.3)$ & $212(23.2)$ & $20(21.5)$ & $90(15.6)$ \\
\hline \multicolumn{5}{|l|}{ Weight $(\mathrm{kg})$} \\
\hline Mean (SD) & $109.9(22.5)$ & $110.4(21.1)$ & $109.3(24.3)$ & $107.0(20.7)$ \\
\hline Unknown/missing (\%) & $530(30.5)$ & $287(31.4)$ & $31(33.3)$ & $153(26.5)$ \\
\hline \multicolumn{5}{|l|}{ Height (m) } \\
\hline Mean (SD) & $1.69(0.10)$ & $1.69(0.10)$ & $1.69(0.10)$ & $1.69(0.10)$ \\
\hline Unknown/missing (\%) & $1166(67.2)$ & $649(71.0)$ & $61(65.6)$ & $380(65.7)$ \\
\hline \multicolumn{5}{|l|}{ BMI $\left(\mathrm{kg} / \mathrm{m}^{2}\right)$} \\
\hline Mean (SD) & $38.1(7.2)$ & $38.2(7.1)$ & $37.1(7.9)$ & $37.6(6.6)$ \\
\hline Unknown/missing (\%) & $533(30.7)$ & $289(31.6)$ & $31(33.3)$ & $154(26.6)$ \\
\hline \multicolumn{5}{|l|}{ HbAlc (\%) } \\
\hline Mean (SD) & $9.49(1.63)$ & $9.49(1.54)$ & $9.66(1.71)$ & $9.64(1.53)$ \\
\hline Unknown/missing (\%) & $218(12.6)$ & $125(13.7)$ & $10(10.8)$ & $44(7.6)$ \\
\hline \multicolumn{5}{|c|}{ Systolic blood pressure $(\mathrm{mmHg})$} \\
\hline Mean (SD) & $134(15)$ & $134(15)$ & $133(15)$ & $133(14)$ \\
\hline Unknown/missing (\%) & $425(24.5)$ & $225(24.6)$ & $28(30.1)$ & $136(23.5)$ \\
\hline \multicolumn{5}{|c|}{ Duration of diabetes (years) } \\
\hline Mean (SD) & $8.1(4.9)$ & $8.0(4.7)$ & $8.6(4.9)$ & $8.3(4.8)$ \\
\hline Unknown/missing (\%) & 0 & 0 & 0 & 0 \\
\hline
\end{tabular}


Table 1 continued

\begin{tabular}{|c|c|c|c|c|}
\hline & \multicolumn{3}{|l|}{ Liraglutide } & \multirow{2}{*}{$\begin{array}{l}\text { Lixisenatide } \\
20 \mu \mathrm{g}(N=578\end{array}$} \\
\hline & All doses $(N=1736)$ & $1.2 \mathrm{mg}(N=914)$ & $1.8 \mathrm{mg}(N=93)$ & \\
\hline \multicolumn{5}{|c|}{ Comorbid disease history, $n(\%)$} \\
\hline Cardiovascular disease & $97(5.6)$ & $40(4.4)$ & $\mathrm{b}$ & $30(5.2)$ \\
\hline Hepatic disease & $24(1.4)$ & $11(1.2)$ & $\mathrm{b}$ & $14(2.4)$ \\
\hline Urinary tract infections & $65(3.7)$ & $25(2.7)$ & $\mathrm{b}$ & $28(4.8)$ \\
\hline \multicolumn{5}{|c|}{ Baseline concomitant diabetes medication, $n(\%)$} \\
\hline Monotherapy & $683(39.3)$ & - & - & $203(35.1)$ \\
\hline Dual therapy & $806(46.4)$ & - & - & $299(51.7)$ \\
\hline Triple therapy & $225(13.0)$ & - & - & $70(12.1)$ \\
\hline
\end{tabular}

$B M I$ body mass index, HbAlc glycated hemoglobin, $S D$ standard deviation

a Percentages were based on patients with available data

b Small number suppression applied for patient numbers $<6$

$>1 \%$ HbA1c reduction $(76.0 \%$ vs. $63.6 \%)$ (Fig. 4). When stratified by diabetes duration, fewer patients tended to achieve each HbA1c target as duration increased (Table 3). Cox regression analysis adjusted for baseline $\mathrm{HbA1c}$ revealed that, compared to the lixisenatide group, patients in the liraglutide group were 2.5 times more likely to achieve HbA1c $<6.5 \%$ and approximately twice as likely to achieve $\mathrm{HbA1c}$ $<7.0 \%$ and $<7.5 \%$ within 12 months of treatment (Table 4). Patients in the liraglutide group were statistically more likely to achieve $>1 \%$ reduction in HbA1c compared to patients in the lixisenatide group (Table 4).

Unadjusted analyses indicated slightly greater BMI and SBP reductions for liraglutide users compared to lixisenatide users (cohort 5 and 6; Fig. 2b, c). However, there was no significant difference in mean change in BMI and SBP between treatment groups (linear regression adjusted for baseline BMI and baseline SBP, respectively) (Table 2). A slightly greater proportion of the liraglutide group (44.9\%) achieved $\geq 3 \%$ reduction in weight compared with the lixisenatide group (40.8\%) (cohort 5; Fig. 4). Cox regression analysis adjusted for baseline weight indicated that patients in the liraglutide group were more likely to achieve $\geq 3 \%$ reduction in weight within 12 months
Fig. 2 12-Month treatment effects of liraglutide (all doses [0.6 mg, $1.2 \mathrm{mg}$, and $1.8 \mathrm{mg}$ per day] and separately for 1.2 and $1.8 \mathrm{mg}$ per day, or lixisenatide $(20 \mu \mathrm{g}$ per day) with respect to a HbAlc (cohort 2) b body mass index (cohort 5), and c systolic blood pressure (cohort 6). Mean values were calculated for patients with available data. $B M I$ body mass index, HbAlc glycated hemoglobin, $S B P$ systolic blood pressure

compared to the lixisenatide group; however, this difference was not statistically significant (Table 4).

The overall number of GP visits recorded within a year from index date was the same for the two groups. Similar trends were seen for face-to-face visits, nurse visits, and phone calls to the GP (Table 5). There were no differences between the groups regarding the mean number of secondary care visits or hospitalizations in the year after index date (Table 5). ANCOVA with adjustment for baseline HbA1c and length of time at risk revealed no significant differences between the two treatment groups.

\section{DISCUSSION}

This real-world observational study indicated that liraglutide-treated individuals experienced 
A

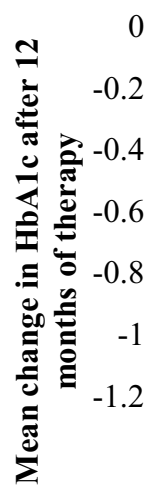

B

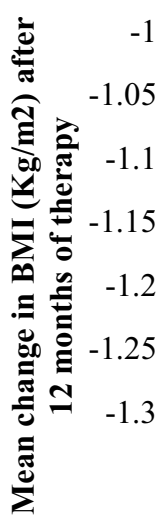

C

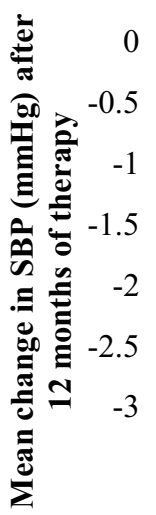

HbA1c (\%)
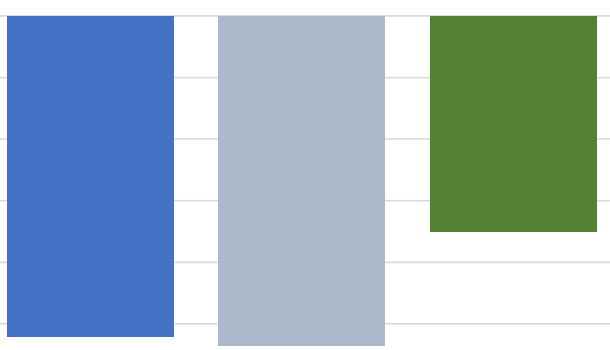

Liraglutide (all doses) $(\mathrm{N}=579)$ Liraglutide (1.2 mg) $(\mathrm{N}=402)$

Liraglutide $(1.8 \mathrm{mg})(\mathrm{N}=40) \quad$ Lixisenatide $(20 \mu \mathrm{g})(\mathrm{N}=213)$

BMI (Kg/m2)
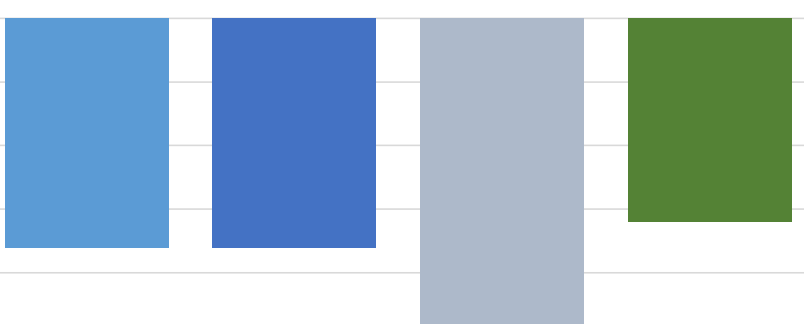

- Liraglutide (all doses) (N=408) E Liraglutide (1.2 mg) (N=290)

Liraglutide $(1.8 \mathrm{mg})(\mathrm{N}=27) \quad$ Lixisenatide $(20 \mu \mathrm{g})(\mathrm{N}=161)$

\section{SBP (mmHg)}
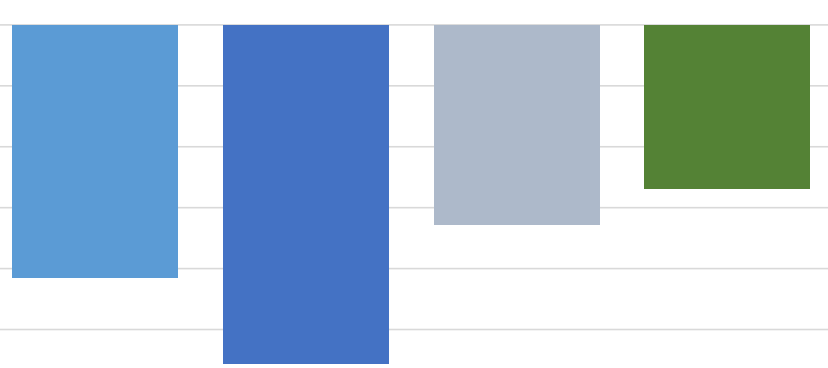

$\square$ Liraglutide (all doses) $(\mathrm{N}=492) \square$ Liraglutide $(1.2 \mathrm{mg})(\mathrm{N}=352)$

$\square$ Liraglutide $(1.8 \mathrm{mg})(\mathrm{N}=33) \quad$ Lixisenatide $(20 \mu \mathrm{g})(\mathrm{N}=174)$ 
Table 2 Linear regression analyses of mean change in HbAlc, BMI, and SBP from baseline to 12 months in patients prescribed liraglutide (all doses [0.6 mg, $1.2 \mathrm{mg}$, and $1.8 \mathrm{mg}$ per day], and separately for $1.2 \mathrm{mg}$ and $1.8 \mathrm{mg}$ per day) versus lixisenatide $(20 \mu \mathrm{g}$ per day)

\begin{tabular}{|c|c|c|c|c|}
\hline & \multicolumn{4}{|c|}{ Linear regression analyses } \\
\hline & $\bar{\beta}$ & 95\% LCL & $95 \% \mathrm{UCL}$ & $p$ value \\
\hline \multicolumn{5}{|c|}{ Mean change in HbAlc: baseline model ${ }^{a}$} \\
\hline Lixisenatide $(20 \mu \mathrm{g})$ & - & & & \\
\hline Liraglutide (all doses) & -0.278 & -0.541 & -0.016 & 0.038 \\
\hline Liraglutide $(1.2 \mathrm{mg})$ & -0.362 & -0.633 & -0.092 & 0.009 \\
\hline Liraglutide (1.8 mg) & -0.417 & -0.965 & 0.130 & 0.135 \\
\hline \multicolumn{5}{|c|}{ Mean change in HbAlc: fully adjusted model ${ }^{\mathrm{b}}$} \\
\hline Lixisenatide $(20 \mu \mathrm{g})$ & - & & & \\
\hline Liraglutide (all doses) & -0.297 & -0.556 & -0.037 & 0.025 \\
\hline Liraglutide (1.2 mg) & -0.395 & -0.663 & -0.128 & 0.004 \\
\hline Liraglutide (1.8 mg) & -0.502 & -1.040 & 0.036 & 0.068 \\
\hline \multicolumn{5}{|c|}{ Mean change in BMI: baseline model ${ }^{c}$} \\
\hline Lixisenatide $(20 \mu \mathrm{g})$ & - & & & \\
\hline Liraglutide (all doses) & -0.009 & -0.488 & 0.469 & 0.969 \\
\hline Liraglutide (1.2 mg) & -0.005 & -0.526 & 0.516 & 0.985 \\
\hline Liraglutide $(1.8 \mathrm{mg})$ & -0.076 & -1.177 & 1.026 & 0.893 \\
\hline \multicolumn{5}{|c|}{ Mean change in SBP: baseline model ${ }^{\mathrm{d}}$} \\
\hline Lixisenatide $(20 \mu \mathrm{g})$ & - & & & \\
\hline Liraglutide (all doses) & -0.404 & -2.644 & 1.837 & 0.724 \\
\hline Liraglutide (1.2 mg) & -0.851 & -3.082 & 1.381 & 0.454 \\
\hline Liraglutide (1.8 mg) & -0.171 & -4.741 & 4.399 & 0.941 \\
\hline
\end{tabular}

$\beta \beta$-coefficient, $B M I$ body mass index, HbAlc glycated hemoglobin, $L C L$ lower confidence limit, SBP systolic blood pressure, $U C L$ upper confidence limit

${ }^{a}$ Linear regression adjusted for treatment and baseline HbAlc only. $N=784$ for the model with all doses of liraglutide and $N=649$ for the model with doses split into 1.2 and $1.8 \mathrm{mg}$

b Linear regression adjusted for all covariates (for baseline HbAlc, age, gender, smoking status, history of hepatic disease, history of urinary tract infection, concomitant medication, history of cardiovascular disease, and diabetes duration). BMI was not adjusted for because of a high level of missing values and an assumed assumption of causal linkage between exposure and outcome. $N=784$ for the model with all doses of liraglutide and $N=649$ for the model with doses split into 1.2 and $1.8 \mathrm{mg}$

${ }^{c}$ Linear regression adjusted for treatment and baseline BMI only. $N=569$ for the model with all doses of liraglutide and $N=478$ for the model with doses split into 1.2 and $1.8 \mathrm{mg}$

${ }^{\mathrm{d}}$ Linear regression adjusted for treatment and baseline SBP only. $N=666$ for the model with all doses of liraglutide and $N=559$ for the model with doses split into 1.2 and $1.8 \mathrm{mg}$ 


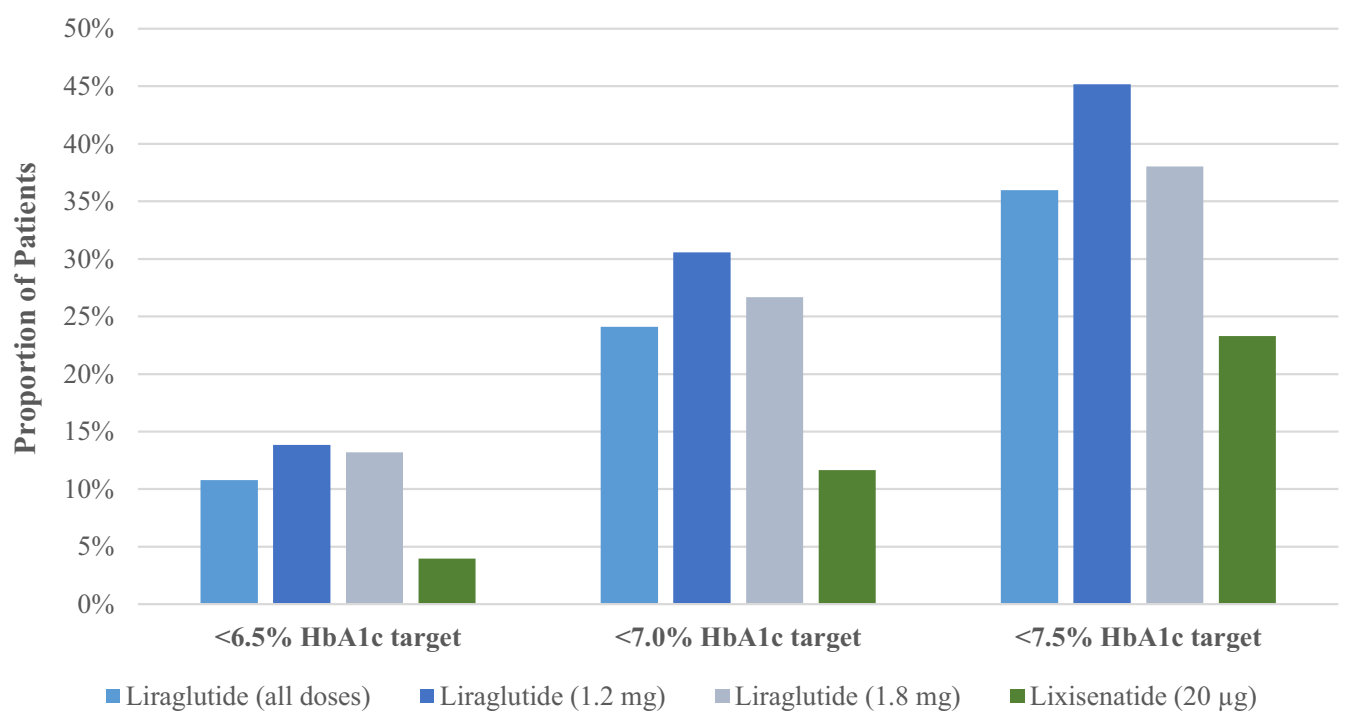

Fig. 3 Proportion of patients in cohort 2 achieving HbAlc levels $<6.5 \%, \quad<7.0 \%$, and $<7.5 \%$ within 12 months of therapy with liraglutide (all doses $[0.6 \mathrm{mg}$, $1.2 \mathrm{mg}$, and $1.8 \mathrm{mg}$ per day] and separately for $1.2 \mathrm{mg}$ and
$1.8 \mathrm{mg}$ per day) or lixisenatide ( $20 \mu \mathrm{g}$ per day). Proportions were calculated on the basis of patients with available data. HbAlc glycated hemoglobin

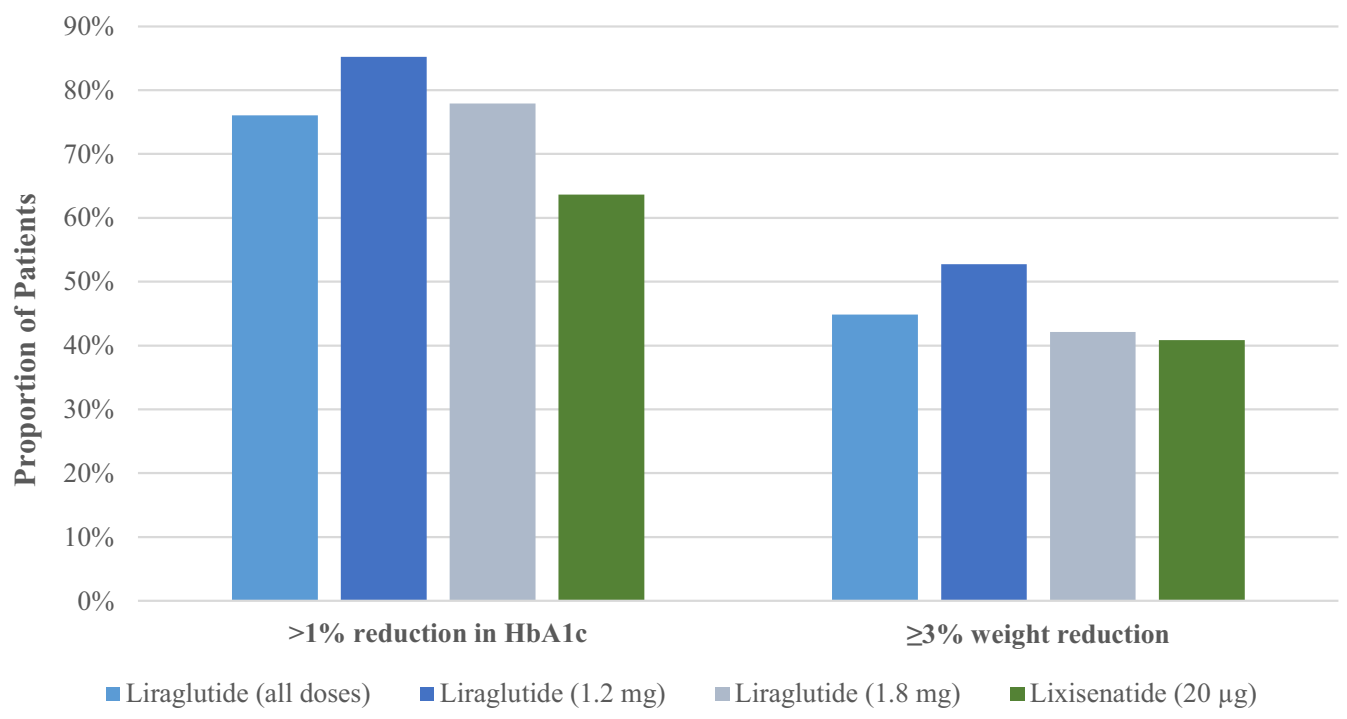

Fig. 4 Proportion of patients achieving $>1 \% \mathrm{HbAlc}$ reduction (cohort 3 ) and $\geq 3.0 \%$ reduction in weight (cohort 4) within 12 months of therapy initiation with liraglutide (all doses [0.6 mg, $1.2 \mathrm{mg}$, and $1.8 \mathrm{mg}$ per day],

and separately for $1.2 \mathrm{mg}$ and $1.8 \mathrm{mg}$ per day) or lixisenatide $(20 \mu \mathrm{g}$ per day). Proportions were calculated on the basis of patients with available data. HbAlc glycated hemoglobin

greater reductions in HbA1c than lixisenatide-treated individuals during the 12 months following treatment initiation. Additionally, a

greater proportion of patients initiating liraglutide achieved $\mathrm{HbA1c}$ targets compared to lixisenatide patients. These findings from 
Table 3 Proportion of patients prescribed liraglutide (all doses [ $0.6 \mathrm{mg}, 1.2 \mathrm{mg}$, and $1.8 \mathrm{mg}$ per day], and separately for $1.2 \mathrm{mg}$ and $1.8 \mathrm{mg}$ per day) or lixisenatide ( $20 \mu \mathrm{g}$ per day) achieving HbAlc and weight reduction targets within $12 \mathrm{months}$ of therapy, stratified by diabetes duration

\begin{tabular}{|c|c|c|c|c|}
\hline & \multicolumn{3}{|l|}{ Liraglutide } & \multirow{2}{*}{$\begin{array}{l}\text { Lixisenatide } \\
20 \mu \mathrm{g} \\
\%(n / N)\end{array}$} \\
\hline & $\begin{array}{l}\text { All doses } \\
\%(n / N)\end{array}$ & $\begin{array}{l}1.2 \mathrm{mg} \\
\%(n / N)\end{array}$ & $\begin{array}{l}1.8 \mathrm{mg} \\
\%(n / N)\end{array}$ & \\
\hline \multicolumn{5}{|l|}{ HbAlc target $<6.5 \%$} \\
\hline Diabetes duration $<5$ years & $16.9(63 / 372)$ & $21.1(47 / 223)$ & a & $11.2(14 / 125)$ \\
\hline Diabetes duration $5-10$ years & $9.9(43 / 436)$ & $13.6(38 / 279)$ & a & a \\
\hline Diabetes duration $>10$ years & $6.2(25 / 405)$ & $7.2(17 / 235)$ & a & a \\
\hline \multicolumn{5}{|l|}{ HbAlc target $<7.0 \%$} \\
\hline Diabetes duration $<5$ years & $30.6(110 / 360)$ & $37.9(83 / 219)$ & $33.3(7 / 21)$ & $22.8(28 / 123)$ \\
\hline Diabetes duration $5-10$ years & $23.7(102 / 431)$ & $29.8(82 / 275)$ & $25.9(7 / 27)$ & $9.7(16 / 165)$ \\
\hline Diabetes duration $>10$ years & $18.7(74 / 395)$ & $24.6(57 / 232)$ & $22.2(6 / 27)$ & $5.1(8 / 158)$ \\
\hline \multicolumn{5}{|l|}{ HbAlc target $<7.5 \%$} \\
\hline Diabetes duration $<5$ years & $45.5(151 / 332)$ & $55.3(114 / 206)$ & $38.9(7 / 18)$ & $34.5(41 / 119)$ \\
\hline Diabetes duration $5-10$ years & $34.1(143 / 419)$ & $43.1(116 / 269)$ & $40.7(11 / 27)$ & $22.6(37 / 164)$ \\
\hline Diabetes duration $>10$ years & $29.8(114 / 383)$ & $38.3(87 / 227)$ & $34.6(9 / 26)$ & $15.5(24 / 155)$ \\
\hline \multicolumn{5}{|l|}{$>1 \% \mathrm{HbAlc}$ reduction } \\
\hline Diabetes duration $<5$ years & $78.8(298 / 378)$ & $86.8(197 / 227)$ & $81.8(18 / 22)$ & $64.3(81 / 126)$ \\
\hline Diabetes duration $5-10$ years & $74.9(331 / 442)$ & $85.9(244 / 284)$ & $85.2(23 / 27)$ & $64.0(110 / 172)$ \\
\hline Diabetes duration $>10$ years & $74.7(307 / 411)$ & $82.9(198 / 239)$ & $67.9(19 / 28)$ & $62.7(101 / 161)$ \\
\hline \multicolumn{5}{|l|}{$\geq 3 \%$ weight reduction } \\
\hline Diabetes duration $<5$ years & $49.0(51 / 104)$ & $58.7(37 / 63)$ & a & $51.6(16 / 31)$ \\
\hline Diabetes duration $5-10$ years & $37.6(38 / 101)$ & $45.2(28 / 62)$ & a & $40.8(20 / 49)$ \\
\hline Diabetes duration $>10$ years & $47.7(51 / 107)$ & $54.2(32 / 59)$ & $54.6(6 / 11)$ & $32.5(13 / 40)$ \\
\hline
\end{tabular}

HbAlc glycated hemoglobin

a Small number suppression applied for patient numbers $<6$

real-world clinical practice are aligned with results from head-to head randomized controlled trials (RCT) where patients in liraglutide treatment groups demonstrated greater reductions in HbA1c levels than patients in lixisenatide treatment groups [4-6].

Baseline clinical characteristics were similar between treatment groups. Approximately three times more patients were prescribed liraglutide compared to lixisenatide, which may be due to longer market availability and thus increased familiarity with liraglutide. Importantly, the present study found that patients prescribed liraglutide or lixisenatide had higher mean baseline HbA1c levels compared to patients in RCTs, but this could be influenced by inclusion criteria thresholds for RCTs [4-6]. In clinical practice, high mean HbA1c could be explained by current UK NICE guidelines recommending GLP-1 RA as a third-line treatment option in 
Table 4 Cox proportional hazards (PH) regression analyses for liraglutide (all doses [0.6 mg, $1.2 \mathrm{mg}$, and $1.8 \mathrm{mg}$ per day]) versus lixisenatide $(20 \mu \mathrm{g}$ per day) to assess the effect of exposure on time to achieving HbAlc and weight reduction targets within 12 months of therapy

\begin{tabular}{|c|c|c|c|c|}
\hline & \multicolumn{4}{|c|}{ Cox $\mathrm{PH}$ regression analyses } \\
\hline & $\overline{\text { HR }}$ & $95 \%$ LCL & $95 \%$ UCL & $p$ value \\
\hline \multicolumn{5}{|l|}{ Probability of achieving $\mathrm{HbAlc}<6.5 \%^{\mathrm{a}}$} \\
\hline Lixisenatide $(20 \mu \mathrm{g})(N=454)$ & - & & & \\
\hline Liraglutide (all doses) $(N=1213)$ & 2.54 & 1.55 & 4.16 & 0.0002 \\
\hline \multicolumn{5}{|l|}{ Probability of achieving $\mathrm{HbAlc}<7.0 \%^{\mathrm{a}}$} \\
\hline Lixisenatide $(20 \mu \mathrm{g})(N=446)$ & - & & & \\
\hline Liraglutide (all doses) $(N=1186)$ & 2.10 & 1.57 & 2.83 & $<0.0001$ \\
\hline \multicolumn{5}{|l|}{ Probability of achieving HbAlc $<7.5 \%{ }^{a}$} \\
\hline Lixisenatide $(20 \mu \mathrm{g})(N=438)$ & - & & & \\
\hline Liraglutide (all doses) $(N=1134)$ & 1.65 & 1.33 & 2.05 & $<0.0001$ \\
\hline \multicolumn{5}{|c|}{ Probability of achieving $>1 \% \mathrm{HbAlc}$ reduction ${ }^{a}$} \\
\hline Lixisenatide $(20 \mu \mathrm{g})(N=459)$ & - & & & \\
\hline Liraglutide (all doses) $(N=1231)$ & 1.29 & 1.13 & 1.47 & 0.0002 \\
\hline \multicolumn{5}{|c|}{ Probability of achieving $\geq 3 \%$ weight reduction ${ }^{\mathrm{b}}$} \\
\hline Lixisenatide $(20 \mu \mathrm{g})(N=120)$ & - & & & \\
\hline Liraglutide (all doses) $(N=312)$ & 1.12 & 0.82 & 1.53 & 0.493 \\
\hline
\end{tabular}

HbAIc glycated hemoglobin, HR hazard ratio, $L C L$ lower confidence limit, $P H$ proportional hazards, $U C L$ upper confidence limit

${ }^{a}$ Cox $\mathrm{PH}$ regression adjusted for baseline HbAlc only

b Cox PH regression adjusted for baseline weight only

patients for whom triple therapy with metformin and two other oral drugs was either not effective, not tolerated, or contraindicated [2].

When assessing the primary outcome, notable differences between the treatment groups were observed for patients with 12 months of available data where patients initiating liraglutide achieved a significantly greater reduction in $\mathrm{HbA} 1 \mathrm{c}$ than those initiated on lixisenatide. This supports previous headto-head RCTs where liraglutide demonstrated superior reductions in HbA1c levels compared with lixisenatide in 26-week [6], 28-day [4], and 8-week RCTs [5].

Additionally, results from an observational study suggest that the observed greater mean reduction in HbA1c may be regarded as clinically relevant [13]. The findings indicated that reducing $\mathrm{HbA} 1 \mathrm{c}$ by $1 \%$ may reduce the risk of diabetes-related death by $21 \%$ and all-cause mortality by $14 \%$. These results, however, could not be reproduced in the three major glucose-lowering trials ADVANCE, ACCORD, and VADT [14-16]. More recently, meta-analyses have found that reducing $\mathrm{HbA1c}$ could significantly reduce the incidence of non-fatal myocardial infarction and coronary heart disease, although this is less certain for all-cause mortality $[17,18]$.

Approximately three-quarters of the liraglutide group and two-thirds of the lixisenatide group achieved $>1 \%$ reduction in HbA1c. These proportions were greater than observed in two 
Table 5 GP, secondary care visits, and hospitalizations of liraglutide users (all doses [0.6 mg, $1.2 \mathrm{mg}$, and $1.8 \mathrm{mg}]$ ) and lixisenatide users during 12 months following initiation of treatment

\begin{tabular}{|c|c|c|c|}
\hline & All patients & Liraglutide & Lixisenatide \\
\hline \multicolumn{4}{|l|}{ All GP visits } \\
\hline Number of patients & 2247 & 1681 & 566 \\
\hline Mean (SD) & $9.8(7.5)$ & $9.7(7.5)$ & $9.8(7.4)$ \\
\hline Median (IQR) & $8.0(5.0,13.0)$ & $8.0(5.0,13.0)$ & $8.0(5.0,13.0)$ \\
\hline \multicolumn{4}{|l|}{ Face-to-face GP visits } \\
\hline Number of patients & 2201 & 1646 & 555 \\
\hline Mean (SD) & $7.2(5.6)$ & $7.2(5.6)$ & $7.2(5.4)$ \\
\hline Median (IQR) & $6.0(3.0,10.0)$ & $6.0(3.0,10.0)$ & $6.0(3.0,9.0)$ \\
\hline \multicolumn{4}{|l|}{ GP nurse visits } \\
\hline Number of patients & 1154 & 865 & 289 \\
\hline Mean (SD) & $3.0(3.0)$ & $3.0(2.8)$ & $3.1(3.3)$ \\
\hline Median (IQR) & $2.0(1.0,4.0)$ & $2.0(1.0,4.0)$ & $2.0(1.0,4.0)$ \\
\hline \multicolumn{4}{|l|}{ GP calls } \\
\hline Number of patients & 1096 & 803 & 293 \\
\hline Mean $(S D)$ & $2.4(2.3)$ & $2.4(2.3)$ & $2.4(2.4)$ \\
\hline Median (IQR) & $2.0(1.0,3.0)$ & $2.0(1.0,3.0)$ & $2.0(1.0,3.0)$ \\
\hline \multicolumn{4}{|l|}{ Secondary care visits } \\
\hline Number of patients & 1687 & 1261 & 426 \\
\hline Mean $(S D)$ & $2.4(1.4)$ & $2.4(1.5)$ & $2.4(1.4)$ \\
\hline Median (IQR) & $2.0(1.0,3.0)$ & $2.0(1.0,3.0)$ & $2.0(1.0,3.0)$ \\
\hline \multicolumn{4}{|l|}{ Hospitalizations } \\
\hline Number of patients & 458 & 346 & 112 \\
\hline Mean (SD) & $1.3(0.7)$ & $1.3(0.7)$ & $1.3(0.6)$ \\
\hline Median (IQR) & $1.0(1.0,1.0)$ & $1.0(1.0,1.0)$ & $1.0(1.0,1.0)$ \\
\hline
\end{tabular}

$I Q R$ interquartile range, $S D$ standard deviation

other real-world liraglutide studies, where just over half of liraglutide users achieved $\geq 1 \%$ HbA1c reduction after 6 months of treatment $[19,20]$. Furthermore, patients initiated on liraglutide had a statistically significant higher probability than lixisenatide users of achieving glycemic targets (including $<6.5 \%$ ) over 12 months. We found that glycemic control targets were attained by a greater proportion of the liraglutide group versus the lixisenatide group. This largely agrees with RCT and real-world data, although the relative proportions of patients achieving these targets were lower than in clinical trials examining liraglutide $1.8 \mathrm{mg}$ $[6,21]$. These lower proportions could be explained by the high mean baseline HbA1c in 
our study, which has previously been identified as a significant predictor of achieving HbA1c targets in response to liraglutide [22]. Response may also be influenced by duration of diabetes; our results indicated a poorer response to the glycemic reduction and control targets with increased duration, a finding consistent with the Association of British Clinical Diabetologists Nationwide Liraglutide Audit [23].

Despite greater improvement in glycemic control with liraglutide use, both liraglutide and lixisenatide use was associated with a similar number of GP, secondary care, and hospital visits in the year following index. Results from a long-term clinical trial have suggested that treatment with liraglutide could be associated with reduced resource use due to a reduction in microvascular and macrovascular events [24].

Our study supports the findings of RCTs and observational studies but carries potential limitations. For some outcomes (i.e., HbA1c, weight), data were not available at both baseline and 12-month follow-up, which could lead to selection bias. However, time windows for measurements were decided according to guidelines for measurement frequency [2] in order to maximize the number of patients in the study. Confounding by indication (i.e., indication bias) resulting from differences in reasons for prescription may lead to systematic bias in favor or against liraglutide. Indication bias may be limited since both liraglutide and lixisenatide belong to the same drug class and both are used as a third-line treatment in the UK. However, the longer market availability and thus familiarity of liraglutide may result in it being preferentially prescribed, as was reflected in the greater number of patients prescribed liraglutide. Multiple linear regression models were applied to mitigate any possible limitations in terms of confounding. The current study was also limited by data contained within the THIN database. Firstly, medication data are based on prescriptions issued rather than prescriptions dispensed and thus it was not possible to confirm that the drug was actually taken by the patient. Secondly, GPs in England received incentives during the study time period for reporting diabetes, while GPs in Wales, Northern Ireland, and Scotland did not. This may have led to an oversampling of patients from English GPs and a higher quality of recording compared to GPs from Wales, Northern Ireland, and Scotland.

\section{CONCLUSIONS}

These data from UK clinical practice provide real-world evidence that liraglutide compared to lixisenatide is associated with greater reductions in $\mathrm{HbA1c}$ and a greater likelihood of achieving HbA1c targets, supporting the results from previous clinical trials.

\section{ACKNOWLEDGEMENTS}

Sponsorship for this study and article processing charges were funded by Novo Nordisk. All named authors meet the International Committee of Medical Journal Editors (ICMJE) criteria for authorship for this manuscript, take responsibility for the integrity of the work as a whole, and have given final approval for the version to be published. All authors had full access to all of the data in this study and take complete responsibility for the integrity of the data and accuracy of the data analysis. Writing assistance in the preparation of this manuscript was provided by Dr. Heidi Eriksen of Aandoo Ltd. Support for this assistance was funded by QuintilesIMS.

Disclosures. M. Feher has received financial support for speaker meeting/consultancy/research from Novo Nordisk and Sanofi. G. Vega-Hernandez, E. Mocevic, B. Buysse, M. Myland, S. Power, L. L. Nystrup Husemoen, J. Kim, and D. R. Witte have nothing to disclose.

Compliance with Ethics Guidelines. This study was reviewed and approved by the UK SRC under protocol 16THIN050 and was performed in accordance with the ethical standards of the 1964 Declaration of Helsinki. This analysis does not contain any new studies with human or animal subjects performed by any of the authors. 
Open Access. This article is distributed under the terms of the Creative Commons Attribution-NonCommercial 4.0 International License (http://creativecommons.org/licenses/ by-nc/4.0/), which permits any noncommercial use, distribution, and reproduction in any medium, provided you give appropriate credit to the original author(s) and the source, provide a link to the Creative Commons license, and indicate if changes were made.

\section{REFERENCES}

1. McGuire H, Longson D, Adler A, Farmer A, Lewin I. Management of type 2 diabetes in adults: summary of updated NICE guidance. BMJ. 2016;353:i1575.

2. National Institute of Health and Care Excellence. Type 2 diabetes in adults: management, NICE guidelines [NG28]. https://www.nice.org.uk/ guidance/NG28/chapter/1. Accessed August 2016.

3. Bain SC. The clinical development program of lixisenatide: a once-daily glucagon-like peptide-1 receptor agonist. Diabetes Ther. 2014;5(2):367-83.

4. Kapitza C, Forst T, Coester HV, Poitiers F, Ruus P, Hincelin-Mery A. Pharmacodynamic characteristics of lixisenatide once daily versus liraglutide once daily in patients with type 2 diabetes insufficiently controlled on metformin. Diabetes Obes Metab. 2013;15(7):642-9.

5. Meier JJ, Rosenstock J, Hincelin-Mery A, Roy-Duval C, Delfolie A, Coester HV, et al. Contrasting effects of lixisenatide and liraglutide on postprandial glycemic control, gastric emptying, and safety parameters in patients with type 2 diabetes on optimized insulin glargine with or without metformin: a randomized, open-label trial. Diabetes Care. 2015;38(7):1263-73.

6. Nauck M, Rizzo M, Johnson A, Bosch-Traberg H, Madsen J, Cariou B. Once-daily liraglutide versus lixisenatide as add-on to metformin in type 2 diabetes: a 26-week randomized controlled clinical trial. Diabetes Care. 2016;39(9):1501-9.

7. Sethi BK, Viswanathan V, Kumar A, Chatterjee S, Chandalia HB. Liraglutide in clinical practice: insights from LEAD programme. Suppl JAPI. 2010;58(June):18-22.

8. Lewis JD, Schinnar R, Bilker WB, Wang X, Strom BL. Validation studies of The Health Improvement Network (THIN) database for pharmacoepidemiology research. Pharmacoepidemiol Drug Saf. 2007;16(4):393-401.

9. Denburg MR, Haynes K, Shults J, Lewis JD, Leonard MB. Validation of The Health Improvement Network (THIN) database for epidemiologic studies of chronic kidney disease. Pharmacoepidemiol Drug Saf. 2011;20(11):1138-49.

10. Martin-Merino E, Fortuny J, Rivero E, Garcia-Rodriguez LA. Validation of diabetic retinopathy and maculopathy diagnoses recorded in a UK primary care database. Diabetes Care. 2012;35(4):762-7.

11. Blak BT, Thompson M, Dattani H, Bourke A. Generalisability of The Health Improvement Network (THIN) database: demographics, chronic disease prevalence and mortality rates. Inform Prim Care. 2011;19(4):251-5.

12. Divino V, DeKoven M, Hallinan S, et al. Glucagon-like peptide-1 receptor agonist treatment patterns among type 2 diabetes patients in six European countries. Diabetes Ther. 2014;5(2):499-520.

13. Stratton IM, Adler AI, Neil HA, et al. Association of glycaemia with macrovascular and microvascular complications of type 2 diabetes (UKPDS 35): prospective observational study. BMJ. 2000;321(7258):405-12.

14. Duckworth W, Abraira C, Moritz T, et al. Glucose control and vascular complications in veterans with type 2 diabetes. N Engl J Med. 2009;360(2):129-39.

15. Heller SR. A summary of the ADVANCE Trial. Diabetes Care. 2009;32(Suppl 2):S357-61.

16. The Action to Control Cardiovascular Risk in Diabetes Study Group. Effects of intensive glucose lowering in type 2 diabetes. $\mathrm{N}$ Engl J Med. 2008;358(24):2545-59.

17. Ray KK, Seshasai SR, Wijesuriya S, et al. Effect of intensive control of glucose on cardiovascular outcomes and death in patients with diabetes mellitus: a meta-analysis of randomised controlled trials. Lancet. 2009;373(9677):1765-72.

18. Turnbull FM, Abraira C, Anderson RJ, et al. Intensive glucose control and macrovascular outcomes in type 2 diabetes. Diabetologia. 2009;52(11):2288-98.

19. Lind $M$, Matsson PO, Linder $\mathrm{R}$, et al. Clinical effectiveness of liraglutide vs sitagliptin on glycemic control and body weight in patients with type 2 diabetes: a retrospective assessment in Sweden. Diabetes Ther. 2016;7(2):321-33.

20. Nyeland ME, Ploug UJ, Richards A, et al. Evaluation of the effectiveness of liraglutide and sitagliptin in 
type 2 diabetes: a retrospective study in UK primary care. Int J Clin Pract. 2015;69(3):281-91.

21. Ostawal A, Mocevic E, Kragh N, Xu W. Clinical effectiveness of liraglutide in type 2 diabetes treatment in the real-world setting: a systematic literature review. Diabetes Ther. 2016;7(3):411-38.

22. Aroda VR, Brett J, Khutoryansky N, Ratner R. Identifying predictors of response to liraglutide in type 2 diabetes using recursive partitioning analysis. Can J Diabetes. 2012;36(5):S45.
23. Thong KY, McGowan BY, Htay T, Pernet A, Kelly C, Rajeswaran $\mathrm{C}$, et al. Insulin treatment and longer diabetes duration both predict poorer glycaemic response to liraglutide treatment in type 2 diabetes: the Association of British Clinical Diabetologists Nationwide Liraglutide Audit. Br J Diabetes Vasc Dis. 2016;15(4):169-72.

24. Marso SP, Daniels GH, Brown-Frandsen K, et al. Liraglutide and cardiovascular outcomes in type 2 diabetes. N Engl J Med. 2016;375(4):311-22. 